\title{
A Qualitative Exploration of Medical Student Empathy During the COVID-19 Pandemic
}

Gabriel Ellison ( $\sim$ Gabriel.Ellison@quinnipiac.edu )

Quinnipiac University

Thomas Pruzinsky

Quinnipiac University

\section{Research Article}

Keywords: COVID-19, Expanded Perspective, empathy, medical education

Posted Date: December 28th, 2021

DOI: https://doi.org/10.21203/rs.3.rs-1121899/v1

License: (c) (i) This work is licensed under a Creative Commons Attribution 4.0 International License. Read Full License 


\section{Abstract}

\section{Background}

There is evidence that medical student self-reported empathy may decline as one progresses through their clinical training. Due to the unprecedented changes to both patient care and medical education caused by COVID-19, it is reasonable to assume that medical student empathy may be impacted. The goal of this July 2020 study was to qualitatively explore how the COVID-19 pandemic might affect medical students' reported experience of empathy.

\section{Method}

Using a semi-structured interview, the authors interviewed 12 medical students, 6 second-year and 6 fourth-year. They selected these groups because of the distinct differences in their clinical experience.

\section{Results}

Data analysis identified 5 major themes: 1) Expanded Perspective (e.g., a feeling of "we're in this together", increased awareness of patient vulnerability) 2) Moral Dilemmas (e.g., difficult decisions faced by students as a result of the pandemic such as weighing educational vs. family responsibilities, students risking their own health to provide the best possible care) 3) Confirmation of Values (e.g., Feeling reaffirmed in decision to enter medicine, feeling the pandemic was "what we signed up for" by entering medical school) 4) Shaping Priorities (e.g., changes in medical specialty or populations of interest) 5) Barriers to Empathy and Adaptive Strategies (e.g., COVID-19 created many physical, psychological, and social barriers to empathy for students, students presented many strategies for ameliorating these barriers). Five students (42\%) reported increased empathy with no students reporting a decrease in empathy due to experiences during the pandemic.

\section{Conclusions}

Participants did not report that their personal experience of empathy for patients was negatively influenced by the COVID-19 pandemic. Many reported that their empathy increased. The observed differences in responses by pre-clinical (second-year) and clinical (fourth-year) students suggests a possible shift in how empathy is experienced and practiced as one progresses through their medical education. The overwhelmingly positive responses to the semi-structured interview, emphasizing appreciation of the opportunity to discuss topics not previously openly discussed, underscores the importance of providing explicit opportunities for students to discuss their emotional/interpersonal experiences within medical education, particularly in difficult times such as the COVID-19 pandemic.

\section{Background}

There is a compelling but inconclusive body of research documenting that some medical students experience a significant decline in their self-reported empathy during the course of their training. ${ }^{1-4}$ 
Medical students report that stress, personal insecurity, and the "hidden curriculum" (e.g. cultural and organizational influences including pressure to compete and impress and emphasis on biomedical learning) are some potential barriers to empathy. ${ }^{5-7}$ Conversely, factors such as higher levels of early patient contact, positive role models, and increased social support are noted as positive influences on empathy development.

Given the major effects of COVID-19 on patient care and medical education, it is reasonable to assume medical student experience of empathy might be influenced by these dramatic changes. For example, student experience of empathy might be influenced by less frequent and/or markedly changed forms patient contact, increased social isolation, and the increased risk to personal health and wellbeing. Additionally, in the early stages of the pandemic, when this study was conducted, this increase in risk was accompanied by a nationwide shortage in personal protective equipment (PPE) as well as initial reports of health care providers becoming infected with the virus, with some experiencing severe illness and death. ${ }^{8,9}$ The alarming nature of this rate of infection was further compounded by limited understanding of the exact mechanisms of virus transmission and uncertainties regarding the most efficacious means of prevention, mitigation, or treatment of the virus. ${ }^{10-13}$ At this time there was no approved COVID-19 vaccination and no clear date for when one might be available. ${ }^{14}$ There is empirical reason to believe that the changes brought on by this global pandemic, such as the increased use of PPE and the pervasive and persistent utilization of social distancing are likely to affect patient - physician communication and relationship formation.15

Therefore, the goal of this study, conducted in early July of 2020, was to qualitatively explore how the COVID-19 pandemic might affect pre-clinical and clinical medical students' reported experience of empathy. Due to the unprecedented and unpredictable nature of the pandemic as well as the dearth of qualitative studies of empathy in medical education, a phenomenological approach was chosen to capture the lived experiences of medical students during this time.

\section{Methods}

\section{Background/Participants}

The Frank H. Netter M.D. School of Medicine at Quinnipiac University (QU) follows a traditional 4-year American medical school model. The first two years are primarily didactics based with limited patient contact of approximately four hours per week. The third and fourth years are centered on clinical experience with students rotating full-time at community medical clinics and hospitals.

As a result of the COVID-19 pandemic, first and second-year students were removed from their weekly clinical experiences in February 2020 with all learning moving remote by March 2020. Third and fourthyear students were removed from in-person clinical rotations in March 2020 with clinical rotations resuming in July 2020. At the time of this study second-year students were on summer break and most 
fourth-year students were preparing to re-enter clinical sites. QU is located in the state of Connecticut which was among the states hit hardest in the earliest waves of the COVID-19 pandemic. ${ }^{16}$

All subjects who were recruited and interviewed were second- or fourth-year medical students at QU. The QU Office of Student Affairs sent an invitation email with a description of the study. To introduce randomization and help reduce selection bias, we sent out recruitment emails to a randomized group of 50 students ( 25 second-year and 25 fourth-year). The Office of Student Affairs then repeated this process once more, at which time we reached an adequate number of respondents. Exclusion criteria included previous mentor-mentee relationship with the first author/interviewer.

We recruited no first-year students to participate because they were not currently enrolled in formal classes, nor were they likely to have extensive clinical experience. We recruited no third-year students as this was the first author's primary medical school cohort. We chose second- and fourth-year students for inclusion due to the distinct differences in the number of clinical experiences. Additionally, much of the empathy erosion literature notes a decline that is most significant during the transition to clinical rotations (between second and third year in the 4-year model). ${ }^{1-4}$. We compensated all participants with a \$20 Amazon gift card. Participants were aware of compensation before enrolling in the study.

\section{Interview Script and Conduction}

The study authors developed a semi-structured interview with 10 questions/prompts based on previously conducted studies of empathy. 6,17,18 They pilot tested this script with a convenience sample of two nonmedical students followed by pilot testing with one second-year and one fourth-year medical student. The first author conducted virtual audio-visual interviews using Zoom Video Communication from July $2^{\text {nd }}$ to July $9^{\text {th }}, 2020$. Interviews were conducted with emphasis on the process of Epoche, which requires the researcher to set aside, as far as humanly possible, preconceived experiences to best understand the experiences of study participants. ${ }^{19}$

Saturation, the point at which it is determined that no new information would be gained from further interviews, was reached after 12 completed interviews ( 6 second-year and 6 fourth-year students). ${ }^{19}$ Additional information including participant age, preferred pronouns, and interview length is found in

Table \#1.

The first author transcribed the interviews verbatim. We stored a key linking identities to all study-related materials on a password-protected USB drive that was deleted following study completion.

\section{Data Analysis}

We completed thematic analysis using a phenomenological approach as detailed in Creswell and Poth. ${ }^{19}$ An outline of the data analysis can be found in Figure \#1. 
The two authors and $\mathrm{SH}$, a practicing clinical psychologist with experience conducting qualitative research, met via Zoom over a series of several extensive meetings to familiarize themselves with the data. They then systematically examined the transcripts line-by-line for significant statements while undergoing the process of horizontalization or treating each statement as having equal worth. ${ }^{19}$ These statements represented an initial set of codes. The first author and $\mathrm{SH}$ then categorized these initial codes into themes and subthemes. Following further data reduction and an iterative coding process, the first author created a finalized codebook of themes/subthemes. $\mathrm{SH}$ and $\mathrm{AH}$, a second-year medical student at a separate university, used this codebook to examine each transcript for the presence or nonpresence of each item. Following this coding, we combined the results into a final data set with all coding discrepancies being adjudicated as needed. From this data, we further reduced, combined, renamed, and eliminated themes and subthemes to produce a finalized set of themes and subthemes. Researchers performed memoing throughout the coding process. ${ }^{19}$ Throughout the analysis process, researchers, except for the first author, were blinded to participant year, preferred pronouns, and personal information.

An outline of the data analysis can be found in Figure \#1.

\section{Results}

We identified 5 major themes based on student responses: Expanded Perspective, Moral Dilemmas, Confirmation of Values, Shaping Priorities, and Barriers to Empathy and Adaptive Strategies.

\section{Expanded Perspective:}

Study participants often reported that their experiences during the pandemic created a feeling that "we're all in this together" which enhanced their experience of empathy. The following bolded and italicized text is direct quotes from the interviews.

I think that because we're kind of experiencing it as a collective, um, collective society, like everyone has gone through lockdown and quarantine and, um, it's affected so many people's lives, um, that because we've all gone through this experience, that allows you to better connect with patients or, um, patient's family members - Student 2 (2nd year)

this pandemic...has affected so many people's lives that just internally I think that it has expanded my sense of empathy, and I think that it's something that I'm going to be more conscious of going forward because I know just how many, like we were all affected by this. This is something insane that we all went through together and like it connected us in, in a way - Student 5 (2nd year)

I think if somebody like if somebody comes to me and they're anxious about going out in public... It's definitely gonna to be this sort of situation where it's like yeah I understand why you're anxious - Student 4 (4th year) 
Students also frequently reported increased awareness of the pandemic's effects on their patient's preexisting financial, social, and psychological vulnerabilities.

I think that if anything, it's increased my empathy because, um, the situation has just made me more aware of how vulnerable people are, um, not only to actual infectious disease agents, but also like emotionally. - Student 6 (4th year)

I think the, uh, for me the thing that kind of stands out about it is the, um, the kind of increasing awareness of, um, the sort of interdependence of social factors and work factors, and family... dynamics on health. And I think when something so wide ranging that is affecting people's finances and childcare and education, um, and of course, physical health. Um, it sort of forces to the front the, the reality that those things are not, um, kind of siloed - Student 9 (2nd year)

One student spoke of their personal experiences of navigating the healthcare system when both they and their parents tested positive for COVID-19, and how this shaped how they view their future as a physician.

...so I had a really drastic experience, and it kind of changed my life, and just being a patient and experiencing how it felt like at times I felt a little bit ignored. At times I felt like I was fighting for my life, I was fighting for my health, I was fighting for, you know, proper healthcare for my parents. That changed my perspective... it like solidified that there, you know, needs to be a better patient-physician relationship, and I am just gonna to do whatever in my power to make that happen for my patients in the future Student 1 (4th year)

I felt like physicians I interacted with didn't care, and that made me upset. So that energy that I have from being upset for how my family and I were treated, I want to use that to make it better with the interactions that I'm involved with because that's what I can control. - Student 1 (4th year)

\section{Moral Dilemmas:}

The pandemic forced students to make difficult moral decisions regarding how they would like to practice medicine now and in the future. For example, fourth-year students had to decide to assume the risk of being infected in order to progress in their clinical training and to provide their patients with the highest possible quality of care.

if it were up to me, I would take that risk on. Again, I don't have a lot to lose. Like I don't live with anyone who's vulnerable necessarily - Student 4 (4th year)

I've had multiple patients dying, and I wanna like hug them and like, there's been a few where I'm not probably supposed to touch them, but I shake their hand and hold their hand anyways because it's important to me. - Student 10 (4th year)

Most students commented on the conflict created between their professional/educational responsibilities and family commitments. Nearly every student reported engaging in social distancing from their family, 
often including being physically isolated from their families when at home, in order to protect them from any potential virus exposure.

I'll have to forfeit quote-unquote my family for my patients, but I feel like that's part of the job even though I'm still a student. - Student 3 (2nd year)

I would, you know, still attend work every day or attend clinic every day...I think I would alter my personal life more, um, than professional.- Student 2 (2nd year)

I signed up for this, they didn't sign up for it - Student 7 (2nd year)

Many fourth-year students were also forced to reevaluate how they wanted to practice medicine.

it's been a really good time, again, for self-reflection, what kind of doctor do I want to be? You know, what kind of advice and guidance do I want to give? What kind of reassurance am I ABLE [emphasis by participant] to give with the uncertainty that's present? -Student 4 (4th year)

I think this is a large like professional identity crisis that I'm actually kind of having right now. And I think that like I have to think about, how do I want to serve my community? And seeing what was happening with COVID... everybody was helping, but some people have certain skills and some people have helpful skills - Student 10 (4th year)

Interacting with patients that may be infected with COVID-19 was not exclusively viewed as something to be feared. Some students expressed that it may instead be a valuable learning experience.

I think I would be a little bit excited just for the experience - Student 7 (2nd year)

I don't wanna say it's... a challenge that I welcome because you obviously don't want people to fall ill. But it's like, that's, that's what...the four years of college, the four years of medical school trains you for, to just be ready and have the information. -Student 8 (4th year)

Some students noted guilt associated with not being able to be as useful as they would like during crisis efforts, with one student stating, I almost feel kind of guilty that like just as a first-year medical student like I did nothing to help!

\section{Confirmation of Values:}

Many students reported their experiences during the pandemic led them to feel as committed as ever in their decision to enter the profession of medicine.

I always consider myself an empathetic person. Um, just, you know, I grew up in a diverse neighborhood. I dealt with diverse situations around healthcare since I was a young age, and that was my motivation to be a doctor. COVID-19 just like, um, confirmed to me like why I want to be a doctor and it made me even more empathetic than I already am to begin with. - Student 1 (4th year) 
It's... definitely made me realize like how important this path is, I think. Like everyone is so reliant on medical professionals right now and like...they're all our heroes right now... So, I think it's made me feel kind of proud to be on this path - Student 5 (2nd year)

Some students reported that their pandemic related experiences reaffirmed their decision to enter a specific specialty or work with a specific population of interest.

I feel more reaffirmed, um, in, you know, the specialty that I want to go into. I anticipate that there's going to be more funding, it seems like. I anticipate that there's going to be more demand and more respect for mental health fields. - Student 4 (4th year) [on their decision to enter Psychiatry]

I'm definitely interested in working with people of color, underserved populations, marginalized communities, and that has definitely not changed due to COVID. If so, that's made me more like excited to work with those populations. - Student 3 (2nd year)

However, the most common confirming sentiment described by students was the belief that by agreeing to enter medical school, they were signing up to help in difficult situations like a pandemic.

I don't want to speak for everyone, that, um, this is kind of, um, the kind of work we signed up for, not necessarily a pandemic...But I do think that most individuals put for the good of the people above, um, themselves and, so I think that when you have that mentality I think it is less likely to affect your care and compassion of patients. - Student 2 (2nd year)

I think that you, when you see this happen, you recognize your decision in medicine to serve - Student 10 (4th year)

You know, no one put a gun to my head when I was applying to medical school. -Student 8 (4th year)

\section{Shaping Priorities:}

Multiple students mentioned changing their desired specialty because of the pandemic.

For one, it changed my specialty. I thought I was gonna be a surgeon and now, um, I'm gonna apply for emergency medicine...I had a lot of things thrown at me and I feel like I was able to handle it. And I feel like that's a big quality for emergency medicine physician - Student 1 (4th year)

sometimes I'm like maybe like that interest that I had in radiology, I should take up on that, um, and it makes me feel a little sad because... I'm making that decision because of my current fear and not really, um, my insight on like long term....unfortunately it has DEFINITELY [emphasis by participant] impacted the specialties I'm interested in - Student 6 (4th year)

After witnessing the effects of health disparities, many students felt inspired to shift the populations with whom they wanted to work. 
I think it's definitely made me think more about being able to like give underserved populations a voice because I know like how brutally affected they've been by this - Student 5 (2nd year)

\section{Barriers to Empathy and Adaptive Strategies:}

Students found that the changes created by COVID-19 lead to novel barriers to the practice of empathy, including: the face being hidden, the loss of the opportunity to share a smile, fear of personal infection, fear of infecting others, a patient's fear, decreased physical touch, social distancing, and increased hesitancy when interacting with patients.

When these interviews were conducted, second-year students had not yet started clinical training and fourth-year students had not yet returned to clinical rotations. Nevertheless, they had many ideas for adapting in response to these barriers, including making explicit statements (e.g., naming the barrier), personal reflection, wearing an enlarged photograph, validating patient feelings, and strictly adhering to prevention protocols to reassure patients.

Second-year students were more likely to comment on physical techniques such as use of pictures of a practitioner on their gown. They were also more likely to mention a loss of educational experiences as a barrier to empathy development. Fourth-year students more often reported use of internal techniques such as self-reflection and were more likely to rely upon safety guidelines to provide themselves and others with reassurance in patient interactions.

\section{Changes in Empathy:}

Five students (42\%), 2 second-year and 3 fourth-year, felt that their personal empathy has or will increase due to experiences during COVID-19. Seven students (58\%) reported no change in empathy. No students felt that their empathy decreased or will decrease due to the pandemic.

I feel like I'm a strong, like an empathetic person in general. Like, I think that's both a strength and flaw of mine. And so, I think that it won't change too much, but I'Il think about COVID as an experience that people have and recognize it and I think because it's so current, I think I'll be more, it'll be more in the forefront of my mind. - Student 10 (4th year)

\section{Participant Response to Interview:}

When specifically asked to reflect on their experience of participating in the interview, every student noted it was a positive one. Many students reported this was their first opportunity to talk about these topics.

I haven't been able to talk about this really with anyone. Um, it was all really, in my mind the whole time, um, that coronavirus is going on and is still going on. So... it was nice to actually say it out in words. Student 6 (4th year)

\section{Discussion}


Empathy is a frequently discussed topic in the context of medical education and should be a focus of concerted attention during this time of dramatic healthcare changes. ${ }^{4,7,20,21}$ Encouragingly, the participants in our study did not feel that their experience of empathy was negatively influenced by the COVID-19 pandemic. In fact, many felt that their empathy increased. In part, this reported increase appears to be related to an oft expressed feeling that "we're in this together". Being 'in this together" may include the fact that patients and physicians - and their loved ones - were all potentially threatened by the virus, including the stress of coping with changes in work and family life, and the ever-present lack of certainty about the spread of the virus as well as treatment and prognosis of becoming ill.

It appears that with this expanded perspective, students feel they will be better able to put themselves in the shoes of their patients as well as be more aware of the importance of empathy within their patient interactions. This may be an example of post-traumatic growth and resilience in the face of these challenges. ${ }^{22,23}$

Students proposed many strategies for reducing the barriers to empathy created by the pandemic. One finding was the differences in strategies proposed by pre-clinical second-year and clinical fourth-year students. Second-year students more often focused on 'external' forms of adapting (e.g., external picture, explicit naming statements) while fourth year students more often described use of 'internal' strategies (e.g. self-reflection). This suggests a possible strategic shift in the way that students experience and practice empathy as they progress through medical training. This may be consistent with research suggesting that the purported declines in empathy scores as one progresses through medical training may be better understood in terms of a strategic/developmental shift in how empathy is practiced clinically. ${ }^{24}$

The overwhelmingly positive responses to the interview process, including the opportunity to discuss topics not previously discussed openly, highlights the importance of providing explicit opportunities for students to discuss their experiences in medical education, particularly in difficult times such as the COVID-19 pandemic.

\section{Limitations}

A limitation to this study is that the interviews were performed by a current medical student peer. It is possible the participants were more comfortable discussing these topics with their peer who may better understand their experiences and be less judgmental. In contrast, there could be a component of social desirability to responses with a peer interviewer. As empathy is often viewed as a necessary and valuable trait within medicine, it is possible that students may be less likely to report a decrease in empathy if present. Additionally, the first author was not blinded to year of study or preferred pronouns throughout process as he personally performed interviews, thus introducing potential bias.

The study invitation email described a discussion of the topic of empathy and COVID-19 which may have led to self-selection of students who are inherently more empathic or open to discussing these topics. Though gender was not a variable investigated in this study, there was a significantly larger number of 
participants indicating preferred pronouns that are traditionally female (she/her/hers) compared to traditionally male (he/him/his) (8:3).

\section{Future Directions}

The COVID-19 pandemic has been a constantly changing phenomenon with complex socioeconomic, emotional, and political components. For example, the initial phase of the pandemic was characterized by a feeling of "we're all in this together". This is in stark contrast to the phase of the pandemic associated with dramatic increases in virus transmission often characterized as "the pandemic of the unvaccinated". ${ }^{25}$ This shift has been precipitated by significant voluntary refusal of the vaccine as well as vaccine and mask mandates. ${ }^{26,27}$ We believe much can be learned by replicating our study at a different time point within the pandemic to examine the shifts in medical student and physician attitudes resulting from the changing healthcare landscape.

Additionally, this study could be expanded to additional medical schools (e.g., different geographic regions) to better generalize the findings. Study participants reported interest in expanding discussion into the areas of health disparities within minority groups and the impacts of COVID-19 upon them, the patient experience of empathy during the pandemic, the impact of the pandemic on physician burnout, and interviewing families of physicians for their perspectives on their loved one's career.

\section{Conclusion}

Participants in this study appear to indicate that their personal empathy did not decrease early in the COVID-19 pandemic, and many reported an increase in empathy. All study participants reported that participating in the interview was a positive experience, particularly the chance to discuss previously undiscussed topics. We believe that medical schools could benefit from providing opportunities for open discussion of emotional/interpersonal experiences, particularly during difficult times such as a global pandemic. Due to the ever-changing healthcare landscape during the pandemic, exploring these topics at different time points would likely provide a rich learning experience.

\section{Abbreviations}

Personal Protective Equipment (PPE), Quinnipiac University (QU)

\section{Declarations}

\section{Ethics Approval and Consent to Participate}

This study received ethical approval from the Quinnipiac University Institutional Review Board (protocol \#08620). All methods were performed in accordance with relevant guidelines and regulations. Signed informed consent was obtained from all participants with consent verbally reiterated prior to interview. 


\section{Consent for Publication}

Not applicable

\section{Availability of Data and Materials}

Semi-structured interview script available in supplemental material 1.

\section{Competing Interests}

The authors declare that they have no competing interests.

\section{Funding}

Funding for participant compensation was provided by the Frank H. Netter M.D. School of Medicine at Quinnipiac University, Office of Student Affairs.

\section{Author Contributions}

GE participated in all phases of the study, including interview script creation, interview conduction, transcription, coding of transcripts, data analysis, and manuscript creation. TP assisted in interview script creation, initial coding of interview transcripts, and manuscript creation. All authors reviewed and approved the final manuscript.

\section{Acknowledgements}

Thank you to Sara J. Hills, PhD, a practicing clinical psychologist, for her assistance throughout the data analysis process. Thank you to Aleksandar Husic, a medical student at Des Moines University School of Medicine, for his assistance with coding transcriptions. Thank you to Douglas McHugh, PhD for his guidance throughout study creation. Thank you to all study participants for their time and effort.

\section{Author's Information:}

At the time of this study, GE was a third-year medical student at the Frank H. Netter M.D. School of Medicine at Quinnipiac University. This research project was completed as part of his medical school graduation capstone project. TP is a clinical health psychologist who has recently retired from the Quinnipiac University Department of Psychology.

\section{References}

1. Hojat M, Shannon SC, DeSantis J, Speicher MR, Bragan L, Calabrese LH. Does Empathy Decline in the Clinical Phase of Medical Education? A Nationwide, Multi-Institutional, Cross-Sectional Study of Students at DO-Granting Medical Schools. Academic medicine: journal of the Association of 
American Medical Colleges. Published online January 21, 2020.

doi:10.1097/ACM.0000000000003175

2. Hojat M, Vergare MJ, Maxwell K, et al. The Devil is in the Third Year: A Longitudinal Study of Erosion of Empathy in Medical School. Academic Medicine. Published online 2009. doi:10.1097/ACM.0b013e3181b17e55

3. Chen DCR, Kirshenbaum DS, Yan J, Kirshenbaum E, Aseltine RH. Characterizing Changes in Student Empathy Throughout Medical School. Medical Teacher. 2012;34(4):305-311. doi:10.3109/0142159X.2012.644600

4. Neumann M, Edelhäuser F, Tauschel D, et al. Empathy Decline and Its Reasons: A Systematic Review of Studies with Medical Students and Residents. Academic Medicine. Published online 2011. doi:10.1097/ACM.0b013e318221e615

5. KH P, DH K, SK K, et al. The relationships between empathy, stress and social support among medical students. International journal of medical education. 2015;6:103-108. doi:10.5116/IJME.55E6.0D44

6. Pohontsch NJ, Stark A, Ehrhardt M, Kötter T, Scherer M. Influences on students' empathy in medical education: An exploratory interview study with medical students in their third and last year. $B M C$ Medical Education. 2018;18(1):231. doi:10.1186/s12909-018-1335-7

7. D J. A meta-ethnography of interview-based qualitative research studies on medical students' views and experiences of empathy. Medical teacher. 2016;38(12):1214-1220. doi:10.1080/0142159X.2016.1210110

8. Cases in the U.S. I CDC. Accessed June 17, 2020. https://www.cdc.gov/coronavirus/2019ncov/cases-updates/cases-in-us.html

9. Cohen J, Rodgers $Y$ van der M. Contributing factors to personal protective equipment shortages during the COVID-19 pandemic. Preventive Medicine. 2020;141:106263. doi:10.1016/j.ypmed.2020.106263

10. Wang W, Xu Y, Gao R, et al. Detection of SARS-CoV-2 in Different Types of Clinical Specimens. JAMA - Journal of the American Medical Association. 2020;323(18):1843. doi:10.1001/jama.2020.3786

11. Sit THC, Brackman CJ, Ip SM, et al. Infection of Dogs with SARS-CoV-2. Nature. Published online 2020. doi:10.1038/s41586-020-2334-5

12. Informal Consultation on Prioritization of Candidate Therapeutic Agents for Use in Novel Coronavirus 2019 Infection. Accessed June 4, 2020. https://www.who.int/publications-detail/informalconsultation-on-prioritization-of-candidate-therapeutic-agents-for-use-in-novel-coronavirus-2019infection

13. Chu DK, Akl EA, Duda S, et al. Physical distancing, face masks, and eye protection to prevent personto-person transmission of SARS-CoV-2 and COVID-19: a systematic review and meta-analysis. The Lancet. 2020;395(10242):1973-1987. doi:10.1016/S0140-6736(20)31142-9

14. Mullard A. COVID-19 vaccine development pipeline gears up. Lancet (London, England). 2020;395(10239):1751. doi:10.1016/S0140-6736(20)31252-6 
15. Wong CKM, Yip BHK, Mercer S, et al. Effect of Facemasks on Empathy and Relational Continuity: A Randomised Controlled Trial in Primary Care. BMC Family Practice. 2013;14:200. doi:10.1186/14712296-14-200

16. CDC COVID Data Tracker. Accessed February 7, 2021. https://covid.cdc.gov/covid-datatracker/\#trends_dailytrendscases

17. Hojat M. Empathy in Health Professions Education and Patient Care. Springer International Publishing; 2016. doi:10.1007/978-3-319-27625-0

18. Mercer SW. The consultation and relational empathy (CARE) measure: development and preliminary validation and reliability of an empathy-based consultation process measure. Family Practice. 2004;21(6):699-705. doi:10.1093/fampra/cmh621

19. Creswell JW, Poth C. Qualitative inquiry \& research design: choosing among five approaches / John W. Creswell, University of Michigan, Cheryl N. Poth, University of Alberta. Poth CN, ed. Qualitative inquiry and research design. Published online 2018.

20. RS C, Z X, AH J, LE S, NC H, DC C. Associations of medical student empathy with clinical competence. Patient education and counseling. 2017;100(4):742-747. doi:10.1016/J.PEC.2016.11.006

21. Fessler MM, Bishop RA, Jabour SM, Vasudevan A. Sandwiches, 6 Feet Apart: Reflections on Community (and Medical School) During COVID-19. Annals of Family Medicine. 2021;19(4):368. doi:10.1370/AFM.2694

22. C N, WH F, A D, et al. The Impact on Medical Students of the $9 / 11$ Attacks on New York's World Trade Center. Teaching and learning in medicine. 2021;33(2):129-138. doi:10.1080/10401334.2020.1818566

23. Rauvola RS, Vega DM, Lavigne KN. Compassion Fatigue, Secondary Traumatic Stress, and Vicarious Traumatization: a Qualitative Review and Research Agenda. Occupational Health Science 2019 3:3. 2019;3(3):297-336. doi:10.1007/S41542-019-00045-1

24. Smith KE, Norman GJ, Decety J. The complexity of empathy during medical school training: evidence for positive changes. Medical Education. 2017;51(11):1146-1159. doi:10.1111/medu.13398

25. C.D.C. Director Warns of a 'Pandemic of the Unvaccinated' - The New York Times. Accessed September 17, 2021. https://www.nytimes.com/2021/07/16/health/covid-delta-cdc-walensky.html

26. Largent EA, Persad G, Sangenito S, Glickman A, Boyle C, Emanuel EJ. US Public Attitudes Toward COVID-19 Vaccine Mandates. JAMA Network Open. 2020;3(12):e2033324-e2033324. doi:10.1001/JAMANETWORKOPEN.2020.33324

27. Siegler AJ, Luisi N, Hall EW, et al. Trajectory of COVID-19 Vaccine Hesitancy Over Time and Association of Initial Vaccine Hesitancy With Subsequent Vaccination. JAMA Network Open. 2021;4(9):e2126882-e2126882. doi:10.1001/JAMANETWORKOPEN.2021.26882

\section{Tables}


Table 1: Participant Demographics

\begin{tabular}{|ll|}
\hline Year of Study: & 6 \\
\hline Second-year & 6 \\
\hline Fourth-year & \\
\hline Age: Mean (range) & $24.3(23-26)$ \\
\hline Second-year: & 28.8 (25-32) \\
\hline Fourth-year: & $26.5(23-32)$ \\
\hline Total: & \\
\hline Preferred Pronouns: & 8 \\
\hline She/her/hers & 3 \\
\hline He/him/his & 1 \\
\hline No response & \\
\hline Interview Length (minutes): & \\
\hline Mean (Range) & $16.2(12-21)$ \\
\hline Second-year: & $20.2(16-27)$ \\
\hline Fourth-year: & $18.2(12-27)$ \\
\hline Total: & \\
\hline
\end{tabular}

Figures 


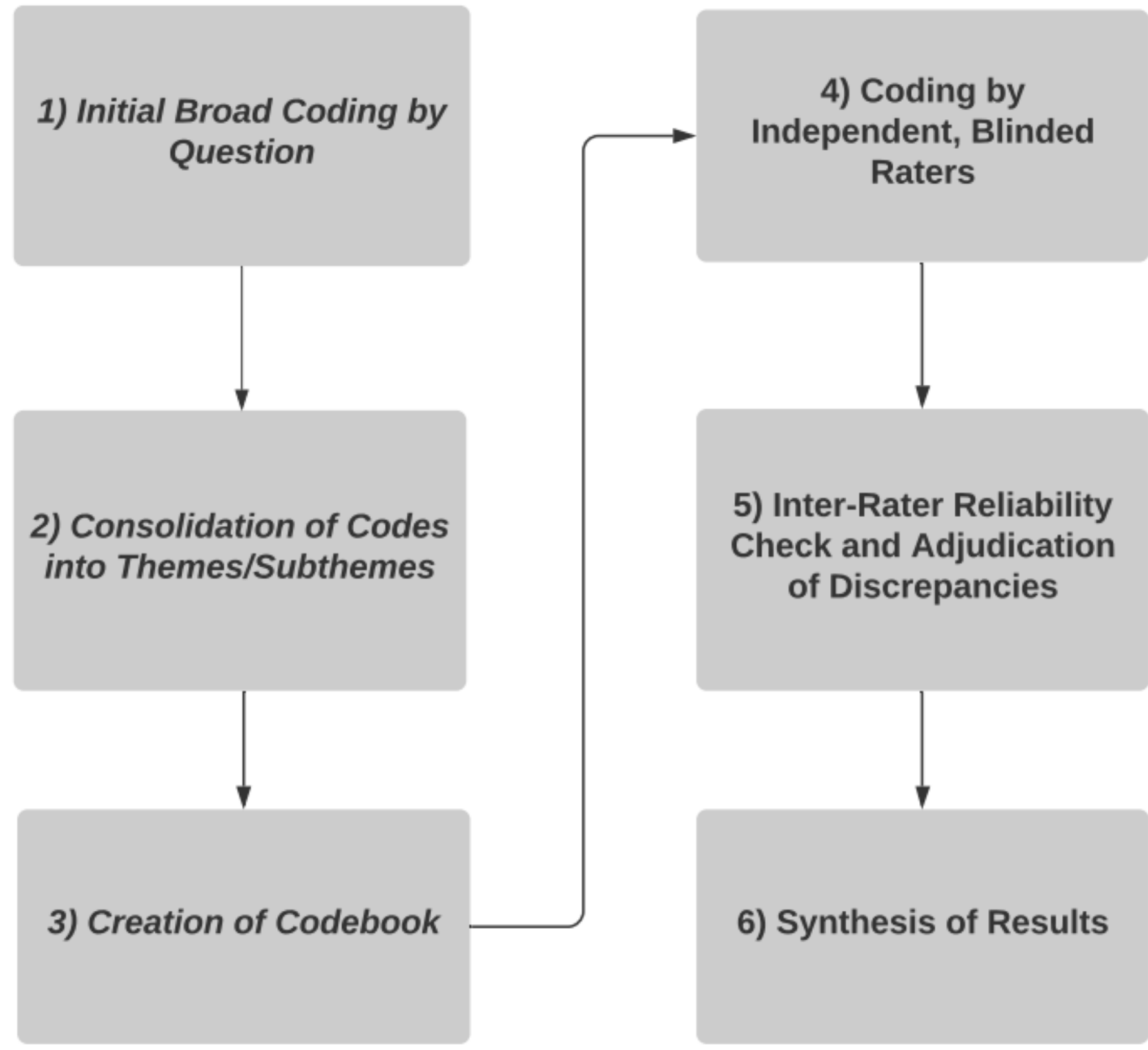

Figure 1

Interview Content Coding and Analysis Sequence

\section{Supplementary Files}

This is a list of supplementary files associated with this preprint. Click to download.

- SupplementalMaterial1.docx 